\title{
Studying Maximum Plantar Stress per Insole Design Using Foot CT-Scan Images of Hyperelastic Soft Tissues
}

\author{
Ali Sarikhani, ${ }^{1}$ Abbas Motalebizadeh, ${ }^{1}$ Sasan Asiaei, ${ }^{2}$ and Babak Kamali Doost Azad ${ }^{1}$ \\ ${ }^{1}$ School of Mechanical Engineering, Iran University of Science and Technology, Tehran 1684613114, Iran \\ ${ }^{2}$ Sensors and Integrated Biomicrofluidics, Mems Laboratory, School of Mechanical Engineering, \\ Iran University of Science and Technology, Tehran 1684613114, Iran \\ Correspondence should be addressed to Sasan Asiaei; asiaei@iust.ac.ir
}

Received 7 March 2016; Revised 1 June 2016; Accepted 27 June 2016

Academic Editor: Laurence Cheze

Copyright (C) 2016 Ali Sarikhani et al. This is an open access article distributed under the Creative Commons Attribution License, which permits unrestricted use, distribution, and reproduction in any medium, provided the original work is properly cited.

\begin{abstract}
The insole shape and the resulting plantar stress distribution have a pivotal impact on overall health. In this paper, by Finite Element Method, maximum stress value and stress distribution of plantar were studied for different insoles designs, which are the flat surface and the custom-molded (conformal) surface. Moreover, insole thickness, heel's height, and different materials were used to minimize the maximum stress and achieve the most uniform stress distribution. The foot shape and its details used in this paper were imported from online CT-Scan images. Results show that the custom-molded insole reduced maximum stress $40 \%$ more than the flat surface insole. Upon increase of thickness in both insole types, stress distribution becomes more uniform and maximum stress value decreases up to $10 \%$; however, increase of thickness becomes ineffective above a threshold of $1 \mathrm{~cm}$. By increasing heel height (degree of insole), maximum stress moves from heel to toes and becomes more uniform. Therefore, this scenario is very helpful for control of stress in $0.2^{\circ}$ to $0.4^{\circ}$ degrees for custom-molded insole and over $1^{\circ}$ for flat insole. By changing the material of the insole, the value of maximum stress remains nearly constant. The custom-molded (conformal) insole which has 0.5 to $1 \mathrm{~cm}$ thickness and $0.2^{\circ}$ to $0.4^{\circ}$ degrees is found to be the most compatible form for foot.
\end{abstract}

\section{Introduction}

One of the reasons for foot pain is unnatural stress distribution [1], and in patients with rheumatoid arthritis, inappropriate stress distribution contributes to elevated foot pain levels [2]. This problem could be easily avoided by utilizing suitable insoles. As a result, minimizing plantar pressure through determination of the proper thickness, heel's height, and elasticity of material used in insoles has a pivotal importance.

The stress distribution on metatarsus area can be measured by experimental methods, such as pedobarography and F-scan [3]. Pedobarograph devices can measure the pressure distribution under the sole for different modes of walking [4]. Emerged in 1978, pedobarography determines the mean pressure and its distribution under the plantar and depicts graphs necessary in qualitative/quantitative analysis for marking the maximum and critical pressure [5]. However, this method is limited to determination of the pressure distribution between the plantar and the smooth surface of the pedograph and cannot be used to examine the pressure distribution on foot, upon using insoles. As a result, it cannot be used to study the pressure distribution in foot due to design of insoles with variable shapes and materials $[4,5]$.

The other experimental method is the F-scan which gives superior results as compared with the latter method. The F-scan systems are commonly used to provide dynamic pressure, force, and timing information for foot function and gait analysis using thin-film sensors [6]. Due to use of flexible, laminar, and sensitive sensors, which can be shaped to fit the foot surface, F-scan sensors can be embedded in insoles of variable designs and record the pressure in real time. Recent versions have become much more functional and are used to record the pressure distribution on foot under different modes of walking/running and in different races and genders [7]. F-Scan is also suitable for design and test of orthotics, offloading diabetic feet, and evaluation/modification of footwear and running techniques in elite 
athletes $[6,7]$. Nevertheless, even the F-scan is unable to measure inner stress and pressure between soft tissue and bony tissue of the foot. As a result, it cannot provide a complete picture from the pressure distribution and its internal interactions on the elemental units of foot and cannot support delicate orthopedic studies for sustainable development of human health. Accordingly, experimental methods such as pedobarography and F-scan are not complete packages for design and analysis of stress on foot, especially, before the costly fabrication stage. Thus, there is a need for modeling and simulation packages, such as Finite Element Method (FEM), which let the biomedical designer acquire engineering insight into the impact of different parameters influencing the stress on foot, before the fabrication of insoles, and avoid the associated costs.

Recent development of computational capabilities along with the advancements in the Finite Element Analysis (FEA), as a numerical method, has created great implications for solving engineering problems, including stress distribution in foot. FEM is capable of filling the gap and calculating inner stress between the soft and bony tissue of foot and, as a result, is suitable for design of insoles. There are a number of studies on FEM analysis of stress distribution in foot, including improper stress distribution in patients suffering from walking disorder after cerebral accidents [8], stress distribution and equivalent stress in injured foot [9], and studying the effect of tendons on stress distribution [10]. In particular, the foot stress distribution with respect to the design and material of the insole has been examined by FEM, considering linear and elastic properties [11]. In addition, the effect of thickness were also considered using FEM and compared with experimental data [12]. However, to the best of our knowledge, the nonlinear, hyperelastic properties were not comprehensively examined, and as a result, the numerical results were not closely following the experimental outcomes.

In this paper, we demonstrate that changing insole designs are playing a major role in changing stress distributions and their magnitude in foot. We also show that stress values do not have the most significant impact and the stress distribution is equally important. We studied the influence of thickness, heel's height, insole shape, and material on reducing the maximum stress exerted on foot. Moreover, we have quantitatively studied the trend, configuration of stress distribution, and its mechanism of variation in foot. In subsequent sections, we will first present the methodology and steps of data acquisition in our analysis. To improve and achieve a high conformity between the numerical simulation results and the experimental outcomes, a 3-dimensional, detailed model of the foot (skeleton) are imported into the FEM model, including the Bone Mineral Density (BDM) and the covering soft tissues. Next, the simulation method and its results will be presented along with verifications. Finally, we will examine the impact of variables considered and discuss the trends seen and general design guidelines.

\section{Methods}

FEM is used for analysis of the inner stress distribution between the soft and bony tissue. To provide valid and

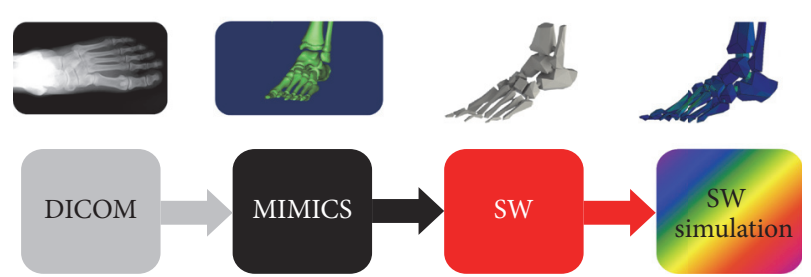

Figure 1: Solid models of bony tissue, soft tissue, and typical insole rendered from real CT-Scan images in a CAD software (SolidWorks), schematic representation.

accurate input data for the FEM simulations, we need a 3D model of the foot with enough details from the foot (skeleton) and Bone Mineral Density (BDM). The insole was designed with CAD software, Especially in SolidWorks and to acquire an accurate model with nearly all details from the foot and the associated BDM, we have captured and then imported scanned images. The 3D model of foot and ankle had been prepared from CT-Scan images that are called DICOM standard format images, commonly used in medical photography and standing for "Digital Imaging and Communications in Medicine" [15, 16]. 750 pictures are captured in three different orientations. These images were imported to MIMICS 10 software. Using this software, soft tissue was separated from bony tissue and became 3D independent models, with on demand transfer of mechanical properties. The output of MIMICS is a shell/hollow 3D model; as a result, it should be reshaped into a solid object before being exported into the FEM software and analysed. Models became solid with SolidWorks 2013 then they were assembled and were simulated with the help of SolidWorks Simulation 2013. The schematic of transferred (regenerated) 3D models in SolidWorks, representing the solid bony tissue, soft tissue, and insole, is shown in Figure 1.

In the analysis, 18 insoles were designed, in which 26 pieces of bones for foot and 2 bones for tibia and fibula were considered and modeled [17]. The soft tissue bears nonlinear hyperelastic properties, acquired from experimental tests, assuming an Ogden hyperelastic model [18]. However, linear elasticity was assumed for the bony tissue and insole and linear displacement with respect to stress in three orientations are considered. Bony tissue is granted full freedom for displacement. Tendons' effects are embedded in the definition of forces and in the same direction of tendons. Mechanical properties were assumed homogeneous. Above assumptions are suitable for this comparative analysis. Materials properties are reported in Table $1[11,13,14]$.

The element type was considered tetrahedral and the number of all assembled model elements are varying between 16000 and 25000 according to shape of insole. The weight of person was considered $70 \mathrm{Kg}$ and static loading, and the race was Caucasian, Aryans. Moreover, half of whole weight force enters the foot in opposite direction by Achilles tendon [11]. Coefficient of friction between insole and foot was considered 0.6 [11]. Thickness and heel height are evaluated for $2000 \mathrm{MPa}$ insole elasticity. Five thicknesses $(0.25,0.5$, $0.75,1$, and $2 \mathrm{~cm}$ ) and three heel heights ( 3 degrees $0.25^{\circ}$, 
TABLE 1: Mechanical properties of bony and soft tissue and insole $[11,13,14]$.

\begin{tabular}{lccc}
\hline & Type & Value & Poisson \\
\hline Insole & Linear elasticity & $\begin{array}{c}0.3 \mathrm{and} \\
2000 \mathrm{MPa}\end{array}$ & 0.4 \\
Soft tissue & $\begin{array}{c}\text { Hyperelastic (Ogden) } \\
\text { (nonlinear elasticity) } \\
\text { Bony tissue }\end{array}$ & $\begin{array}{c}\text { Experimental } \\
\text { test }\end{array}$ & 0.45 \\
\hline
\end{tabular}

$0.5^{\circ}$, and $1^{\circ}$ ) for custom-molded (conformal) insole and three thicknesses $(0.25,0.5$, and $1 \mathrm{~cm})$ and four heel heights $(4$ degrees $0.25^{\circ}, 0.5^{\circ}, 1^{\circ}$, and $2^{\circ}$ ) for flat insole are examined. The custom-molded insole, or the conformal insole, has covered the whole foot such that it completely takes the format of the foot, covering/filling all the lumps and bumps of the foot, while the flat insole has a flat surface where foot interacts with the insole over a flat surface. Soft tissues were assumed homogeneous and Achilles tendon was considered only and other tendons and ligaments were neglected. Our results on the distribution of stress, its maximum, and uniformity have a high conformity with the experimental reports on the flat insole and the custom-molded design. In more detail, our simulation results on the maximum stress in the rear foot region (rear heel) have less than 5\% of difference with the experimental results for a $4 \mathrm{~mm}$ thickness of flat insole. Moreover, all our simulation results are exhibiting the same trend as the experimentally published reports on the flat and the custom-molded insoles [12].

\section{Results and Discussion}

The shape of the insole greatly influences the maximum stress and its distribution. Figure 2 depicts the general stress distribution pattern on foot, drawn for comparison between the two type of insoles considered here, which are the custommolded (Figure 2(a)) and flat (Figure 2(b)) insoles. The two insoles have the same thickness, elasticity, and degree. The custom-molded insole has lower maximum stress, which is $40 \%$ less than flat insole. The maximum stress in the flat insole is around $100 \mathrm{KPa}$ while it is around $60 \mathrm{KPa}$ in the custom-molded insole. Moreover, the custom-molded insole has a better (more uniform) stress distribution, as compared with the flat insole. In the latter case, the maximum stress on the heel region is $84 \%$ higher than maximum stress on the metatarsal, and in mid foot, their values range between $97 \mathrm{KPa}$ and $52 \mathrm{KPa}$. On the other hand, in the custom-molded insole (conformal), the maximum stress on the heel region is only $4 \%$ higher than maximum stress on the metatarsal, which is presumably due to the more conformity of the insole with natural foot shape, in the custom-molded design. In other words, in the custom-molded design the insole has been shaped to support the foot in almost all directions and this will lead to a more uniform stress distribution and less maximum stress on foot.

The result for custom-molded insole in different thicknesses and different elasticities was computed and schematic was drawn in Figure 3. Upon increasing the thickness
TABLE 2: Maximum stress in heel, mid foot, and metatarsal regions for two different materials and custom-molded insole. The thickness of insoles is $2 \mathrm{~cm}$.

\begin{tabular}{lccc}
\hline Insole's material & $2000 \mathrm{MPa}$ & $1000 \mathrm{MPa}$ & $0.3 \mathrm{MPa}$ \\
\hline Rear heel & 57.60 & 58.26 & 57.01 \\
Heel & 60.87 & 60.22 & 60.87 \\
Mid foot & 61.92 & 61.89 & 61.97 \\
Metatarsal & 58.185 & 59.05 & 62.7 \\
\hline
\end{tabular}

from $0.25 \mathrm{~cm}$ to $2 \mathrm{~cm}$, the maximum stress in the heel decreases from $65.94 \mathrm{KPa}$ to $60.87 \mathrm{KPa}$ and for metatarsal increases from $52.136 \mathrm{KPa}$ to $61.92 \mathrm{KPa}$. The figure presents the variation of maximum stress by changing the thickness for custom-molded insoles and it demonstrates that, above $0.75 \mathrm{~cm}$, maximum stress remains relatively constant in all regions; as a result, the optimum thickness lies between 0.5 and $1 \mathrm{~cm}$.

The result for flat insole in four different thicknesses and two different elasticities was drawn in Figure 4. By increasing the thickness from $0.25 \mathrm{~cm}$ to $1 \mathrm{~cm}$, the maximum stress for heel region decreases from $100.1 \mathrm{KPa}$ to $90.9 \mathrm{KPa}$ and for metatarsal region increases from $1.36 \mathrm{KPa}$ to $2.24 \mathrm{KPa}$. If maximum stress is decreased, stress distribution deviates from uniformity, according to Figure 4. The huge concentrated stress around $100 \mathrm{Kpa}$ in heel region shows that stress is not well distributed in the flat insole. Moreover, the figure provides evidence that increase of thickness becomes ineffective above a certain threshold, around $0.75 \mathrm{~cm}$. Accordingly, thicknesses between 0.5 and $0.75 \mathrm{~cm}$ are favorable.

Maximum stress is nearly independent of the insole materials, revealed from our simulation results. We have examined the effect of insole material and its impact on the maximum stress on different regions of foot for the custom-molded insole and for a typical $2 \mathrm{~cm}$ thickness of the insole. The results are summarized in Table 2. The table reports the simulations results for two typical high (very hard around the young module of bone) and low young (very soft insoles) modules of $2000 \mathrm{Mpa}$ and $0.3 \mathrm{Mpa}$ and shows all regions experiencing minor changes in the stress amount. This observation is due to the fact that the amount of stress experienced by foot is mainly a function of geometry and insole configuration with respect to foot, not the material of the insole.

In Figures 5 and 6, the maximum stress and its distribution schematics are plotted for custom-molded and flat insoles in $0.5 \mathrm{~cm}$ thickness and $2000 \mathrm{MPa}$ elasticity with different insole degrees (heel heights). Increase of insole degree, or heel height, becomes harmful above $0.3^{\circ}$ degrees, in the custom-molded design, demonstrated, respectively, in Figure 5. However, for the custom-molded design, in low degree insoles below $0.3^{\circ}$, it is useful to increase the insole degree as it reduces the maximum stress imposed on foot. The maximum stress in rear heel region decreases from $62.32 \mathrm{KPa}$ to $51.42 \mathrm{KPa}$ but in metatarsal increases from $53.69 \mathrm{KPa}$ to $73.16 \mathrm{KPa}$, by increasing degree from $0^{\circ}$ to $1^{\circ}$. According to Figure 5 , it is recommended to use an optimized range of insole degrees to minimize stress values in every region of the 


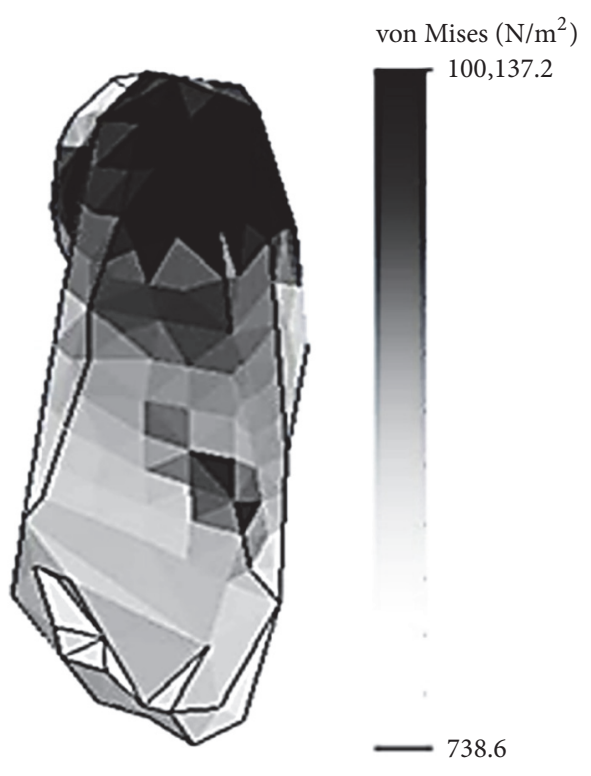

(a)
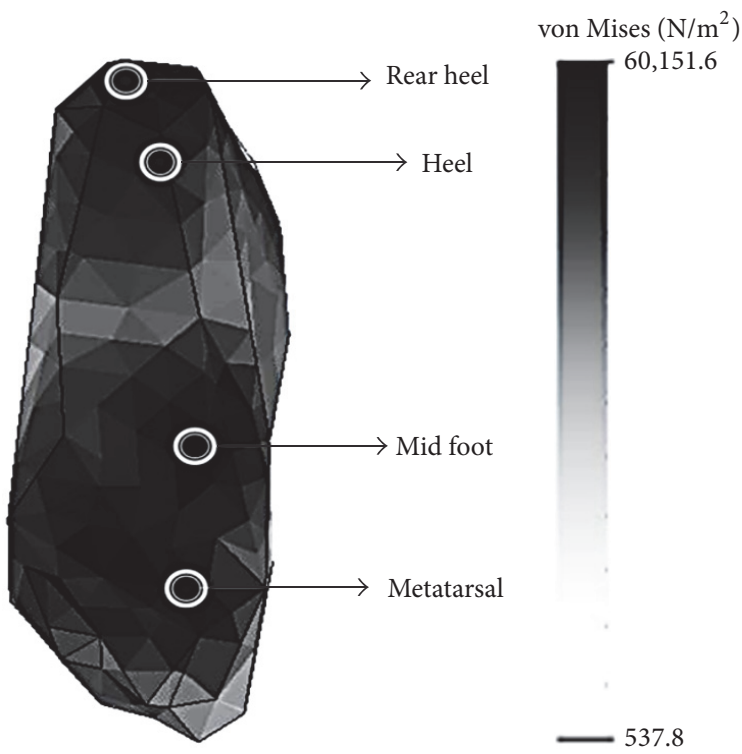

(b)

Figure 2: Flat (a) and custom-molded (b) insoles stress graph. Insoles thickness, elasticity, and degree are $0.5 \mathrm{~cm}, 2000 \mathrm{MPa}$, and $0^{\circ}$ regularly. The maximum stress in the custom-molded insole is $40 \%$ less than the flat insole. Moreover, the stress has a more uniform spread in the custom-molded insole.
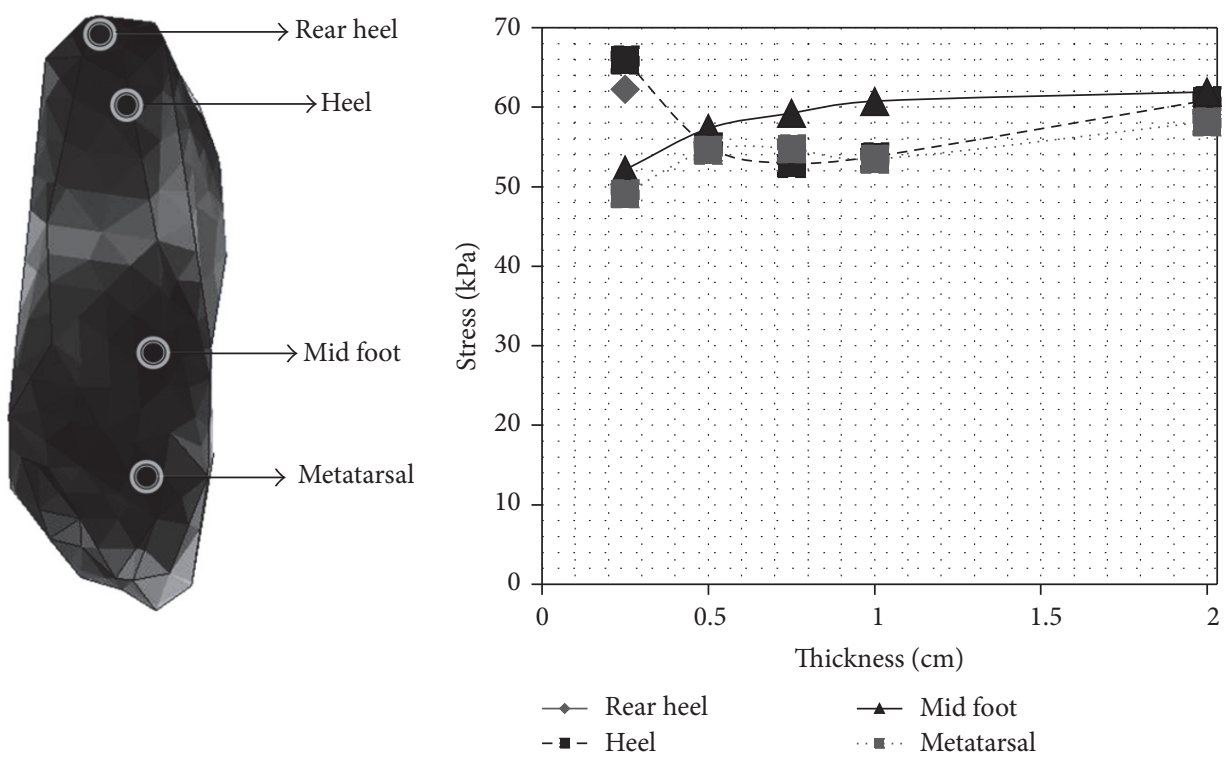

FIGURE 3: Variation of stress value in each region by changing the thickness for custom-molded insoles. The stress is well distributed over the whole foot. Moreover, increasing the thickness does not necessarily lead to less maximum stress after around $0.75 \mathrm{~cm}$ thickness of the insole.

foot. Results show that this desired degree is about $0.2^{\circ}$ to $0.4^{\circ}$ for custom-molded insole design.

For flat insole design, the maximum stress in heel region decreases from $96.291 \mathrm{KPa}$ to $85.385 \mathrm{KPa}$ but in metatarsal increases from $1.78 \mathrm{KPa}$ to $2.06 \mathrm{KPa}$, by increasing degree from $0^{\circ}$ to $2^{\circ}$. Figure 6 shows that increase of degree becomes harmful above a certain threshold but in low degrees it can be useful. Therefore, the results suggest utilizing the optimal range of insole degree to minimize stress values in every region of the foot. This desired degree is above $1^{\circ}$ for flat insole design, revealed from simulation results.

\section{Conclusion}

In this paper, we have investigated the optimal range of insole design parameters through FEM modeling and simulation of plantar stress distribution, for the flat surface and the custommolded surface insoles. Insole thickness, heel's height, and 

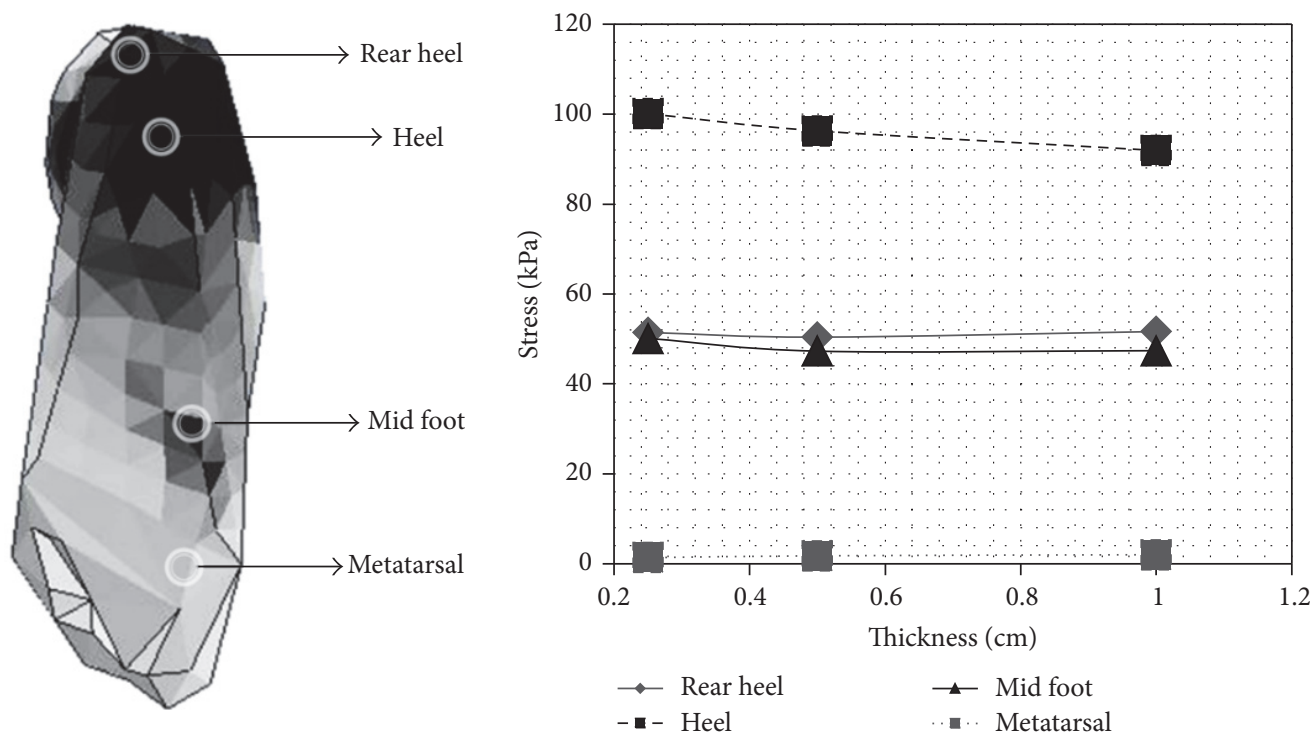

FIGURE 4: Variation of stress value in each node by changing the thickness for flat insoles. The stress is concentrated in two main regions: rear heel and heel. Moreover, increasing the thickness of insole does not necessarily lead to less maximum stress.

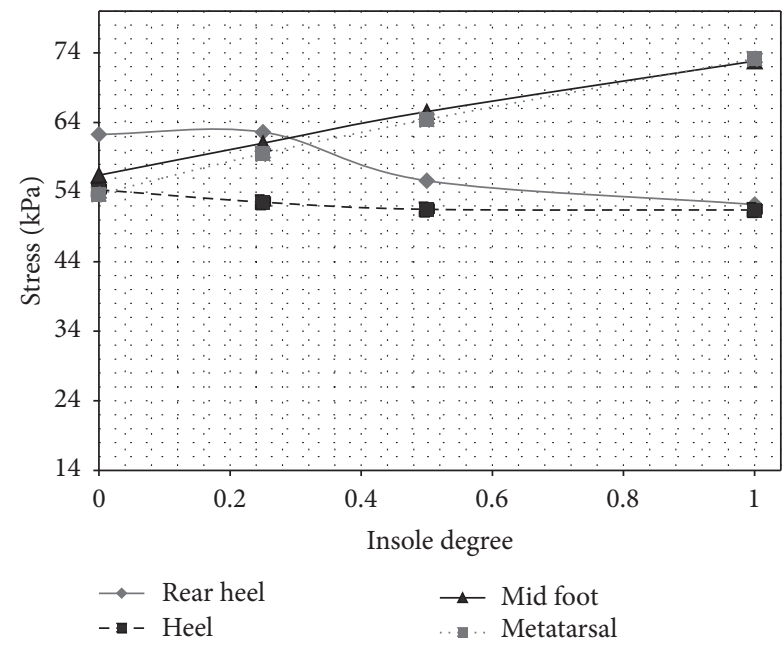

FIGURE 5: Variation of maximum stress value by changing the degrees in metatarsal, mid foot, and heel regions for custom-molded insole. Increase of insole degree (or the heel height) does not necessarily reduce the maximum stress in foot; the recommended range is around $0.2^{\circ}$ to $0.4^{\circ}$.

different materials were used to determine the maximum stress and achieve the settings that yield the most uniform stress distribution. The detailed simulation was carried out for a typical $70 \mathrm{~kg}$ person importing the full details of the foot from CT-Scan images. Softer insoles had almost the same stress distribution and maximum stress values as harder insoles. The shape of insoles plays an important role in leveling the stress on foot and decreasing the maximum stress. Custom-molded insoles had considerably better stress distribution and much less maximum stress (around $40 \%$ ) compared to flat insoles, which is very important in

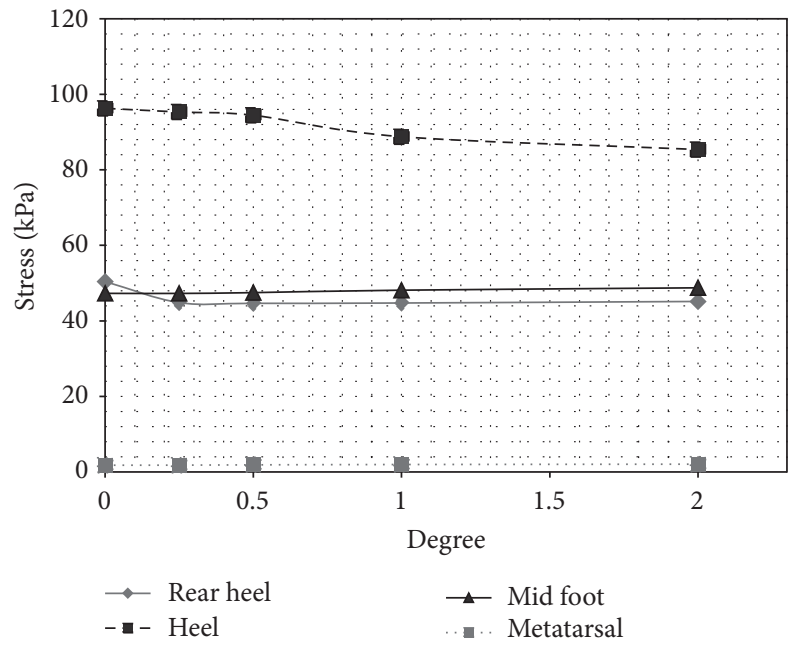

FIGURE 6: Variation of maximum stress value by changing the degrees in metatarsal, mid foot, and heel regions for flat insole. Increase of insole degree (or the heel height) does not necessarily reduce the maximum stress in foot; the recommended range is above $1^{\circ}$.

fabrication and selection of comfortable insoles. Increase of thickness makes the stress distribution more uniform and decreases the maximum stress value up to $10 \%$, in both insole types. However, increase of thickness becomes ineffective over $0.75 \mathrm{~cm}$ thicknesses. By tiny increase of insole degree (heel height) from $0.2^{\circ}$ to $0.4^{\circ}$ for custom-molded insole and above $1^{\circ}$ for flat insole, maximum stress value decreases at least $4 \%$ and stress distribution becomes more uniform. Upon further increase of insole degree, maximum stress moves from heel to metatarsal and by sequent elevations, maximum stress becomes critically high and this fact is not desired. 


\section{Competing Interests}

The authors declare that there are no competing interests regarding the publication of this paper.

\section{Acknowledgments}

This research was financially supported by the Ministry of Science, Research and Technology (MSRT), Iran. The authors would like to acknowledge the products and services provided by MSRT that facilitated this research, including the CAD software.

\section{References}

[1] J. J. Holewski, K. M. Moss, R. M. Stess, P. M. Graf, and C. Grunfeld, "Prevalence of foot pathology and lower extremity complications in a diabetic outpatient clinic," Journal of Rehabilitation Research and Development, vol. 26, no. 3, pp. 35-44, 1989.

[2] M. Yavuz, E. Husni, G. Botek, and B. L. Davis, "Plantar shear stress distribution in patients with rheumatoid arthritis: relevance to foot pain," Journal of the American Podiatric Medical Association, vol. 100, no. 4, pp. 265-269, 2010.

[3] R. Hosein and M. Lord, "A study of in-shoe plantar shear in normals," Clinical Biomechanics, vol. 15, no. 1, pp. 46-53, 2000.

[4] C. H. Chang, F. Miller, and J. Schuyler, "Dynamic pedobarograph in evaluation of varus and valgus foot deformities," Journal of Pediatric Orthopaedics, vol. 22, no. 6, pp. 813-818, 2002.

[5] R. J. Minns and R. A. Sutton, "Pressures under the ischium detected by a pedobarograph," Engineering in Medicine, vol. 11, no. 3, pp. 111-115, 1982.

[6] J. Woodburn and P. S. Helliwell, "Observations on the F-Scan in-shoe pressure measuring system," Clinical Biomechanics, vol. 11, no. 5, pp. 301-304, 1996.

[7] A. Wilharm, C. Hurschler, T. Dermitas, and M. Bohnsack, "Use of Tekscan K-scan sensors for retropatellar pressure measurement avoiding errors during implantation and the effects of shear forces on the measurement precision," BioMed Research International, vol. 2013, Article ID 829171, 7 pages, 2013.

[8] T.-M. Chu and N. P. Reddy, "Stress distribution in the anklefoot orthosis used to correct pathological gait," Journal of Rehabilitation Research and Development, vol. 32, no. 4, pp. 349360, 1995.

[9] A. Özkan, H. Atmaca, I. Mutlu, T. Çelik, L. Ugur, and Y. Kisioglu, "Stress distribution comparisons of foot bones in patient with tibia vara: a finite element study," Acta of Bioengineering and Biomechanics, vol. 15, no. 4, pp. 67-72, 2013.

[10] J. Liang, Y. F. Yang, G. R. Yu, W. X. Niu, and Y. B. Wang, "Deformation and stress distribution of the human foot after plantar ligaments release: a cadaveric study and finite element analysis," Science China Life Sciences, vol. 54, no. 3, pp. 267-271, 2011.

[11] J. T.-M. Cheung and M. Zhang, "A 3-dimensional finite element model of the human foot and ankle for insole design," Archives of Physical Medicine and Rehabilitation, vol. 86, no. 2, pp. 353358, 2005.

[12] S. Goske, A. Erdemir, M. Petre, S. Budhabhatti, and P. R. Cavanagh, "Reduction of plantar heel pressures: insole design using finite element analysis," Journal of Biomechanics, vol. 39, no. 13, pp. 2363-2370, 2006.

[13] A. Gefen, M. Megido-Ravid, Y. Itzchak, and M. Arcan, "Biomechanical analysis of the three-dimensional foot structure during gait: a basic tool for clinical applications," Journal of Biomechanical Engineering, vol. 122, no. 6, pp. 630-639, 2000.

[14] Y. P. Zheng, Y. K. C. Choi, K. Wong, S. Chan, and A. F. T. Mak, "Biomechanical assessment of plantar foot tissue in diabetic patients using an ultrasound indentation system," Ultrasound in Medicine and Biology, vol. 26, no. 3, pp. 451-456, 2000.

[15] R. Noumeir, "Benefits of the DICOM structured report," Journal of Digital Imaging, vol. 19, no. 4, pp. 295-306, 2006.

[16] M. Mustra, K. Delac, and M. Grgic, "Overview of the DICOM standard," in Proceedings of the 50th International Symposium ELMAR, vol. 1, pp. 10-12, Zadar, Croatia, September 2008.

[17] C. L. Riegger, "Anatomy of the ankle and foot," Physical Therapy, vol. 68, no. 12, pp. 1802-1814, 1988.

[18] T. Hu and J. P. Desai, "Characterization of soft-tissue material properties: large deformation analysis," in Medical Simulation, vol. 3078, pp. 28-37, Springer, Berlin, Germany, 2004. 


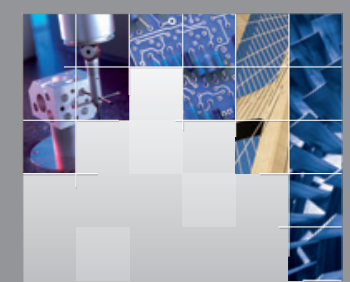

\section{Enfincering}
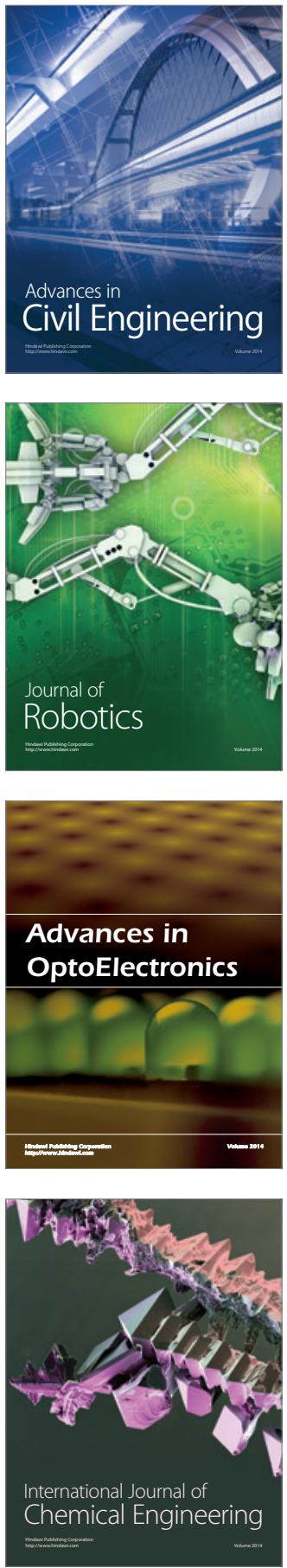

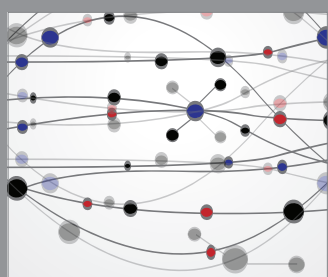

The Scientific World Journal

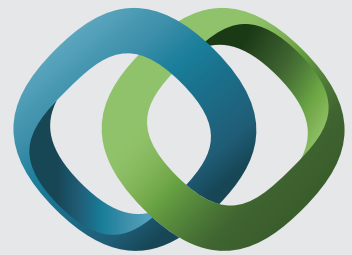

\section{Hindawi}

Submit your manuscripts at

http://www.hindawi.com
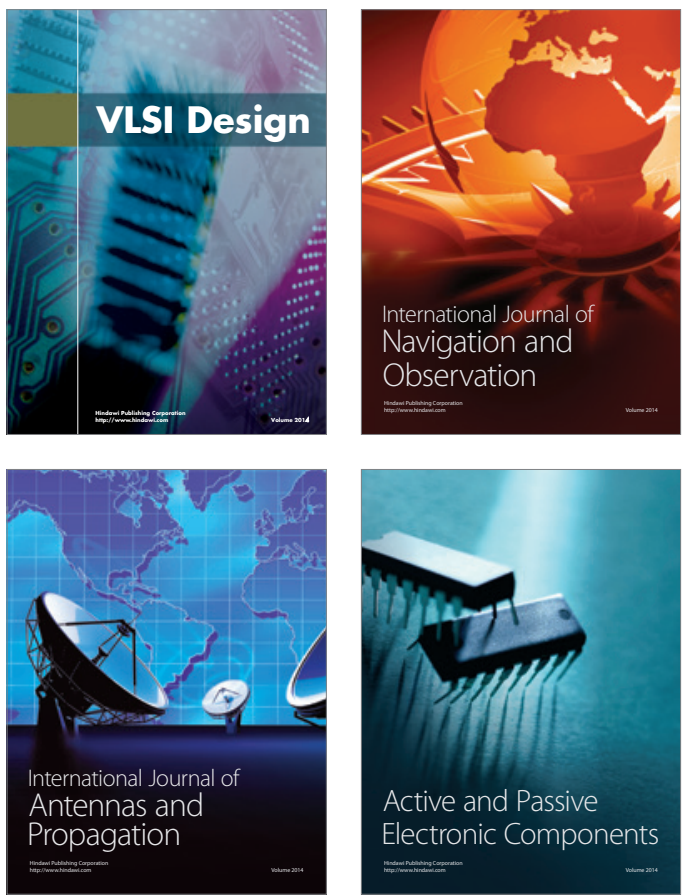
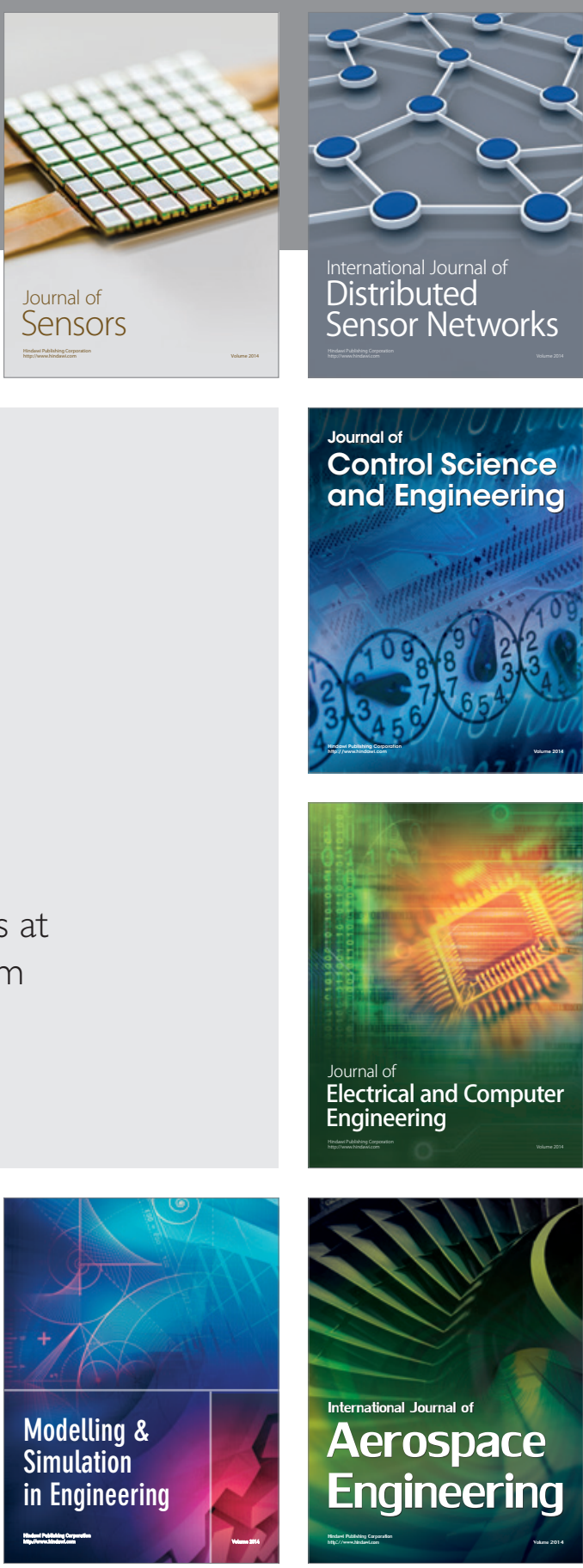

International Journal of

Distributed

Sensor Networks

Journal of

Control Science

and Engineering
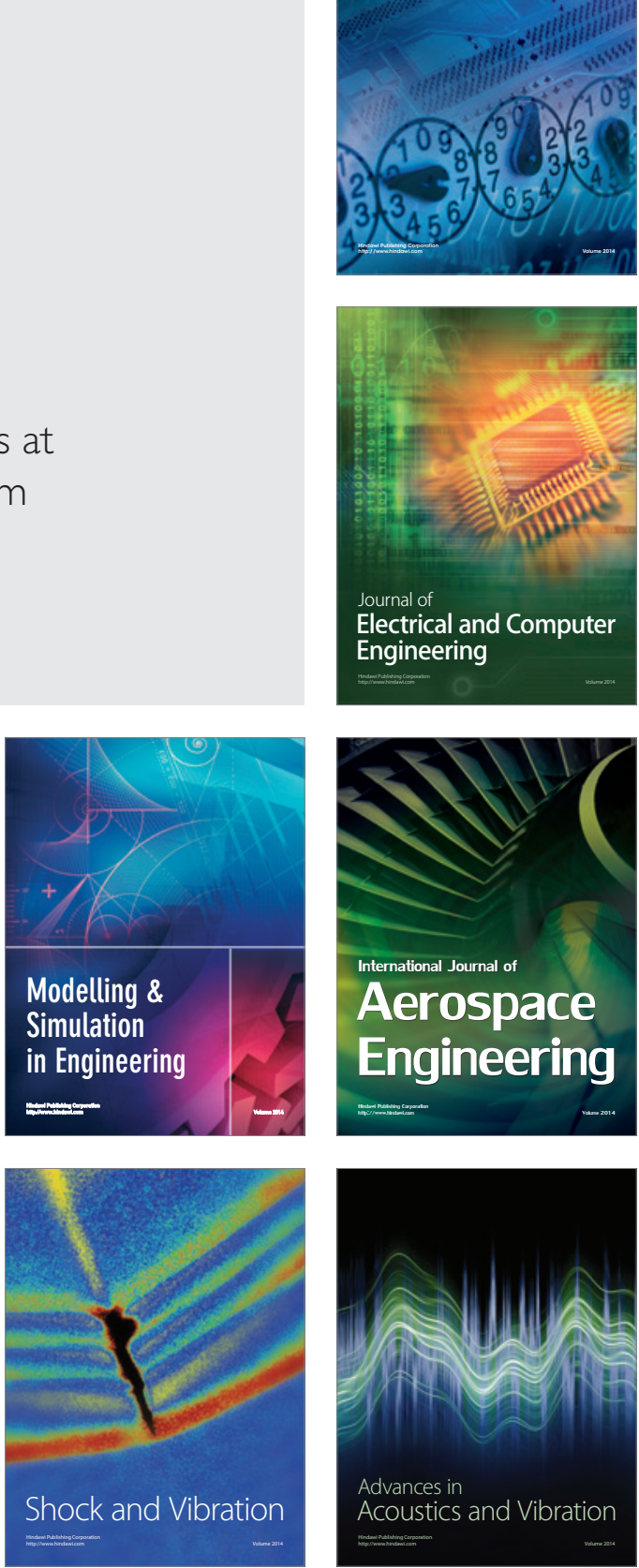